\title{
A Performance Evaluation Research on Collaborative Operation between Logistics Enterprise and Manufacturing Enterprise
}

\author{
Chouyong Chen*, Xin Sun and Bin Ding \\ School of Management, Hangzhou Dianzi University, Hangzhou, 310000, China
}

\begin{abstract}
With the continuous development of economy and technology, the importance of logistics services has gained more and more attention in the whole industry chain. Collaborative operation between manufacturing companies and logistics companies can improve operational efficiency and save the cost for the enterprise by the way of simplify the transaction process in the supplying chain and reducing the transaction costs. In this paper, through the deep investigation and analysis of the collaborative operation between logistics and manufacture, combing the previous studies and opinions of the relevant professors, a series of evaluation indicator has been teased out, which is suitable for evaluating the collaboration performance. Meanwhile, a multistage fuzzy comprehensive evaluation system is constructed by using analytic hierarchy process and fuzzy comprehensive analysis method.
\end{abstract}

Keywords: Collaborative operation, evaluation system, logistics enterprise, manufacturing enterprise.

\section{INTRODUCTION}

Collaborative Logistics is a logistics system cooperated and organized by logistics enterprise and manufacturing enterprise. This complex system can realize the logistics information and resources sharing, minimize the logistics cost and improve the logistics efficiency. With the increasingly fierce market competition, under the situation that the performance evaluation system is lacked, the cooperation between manufacture and logistics is starved for to make sure the continuous improvement of the whole competitive advantages.

Based on the practice and experience of the western developed countries, collaborative logistics can not only lower the logistics cost of manufacture but also support the welldeveloped service for the manufacturing enterprise, making the efficient performance of logistics enterprise and manufacturing enterprise to optimal state. In China, logistics service is still at the primary stage of development. Many logistics companies only provide some traditional services such as storage, transportation and delivery. Since the collaborative logistics is on the initial stage, the credibility is low, the mechanism of interests coordination and distribution is insufficient, and the collaborative operation is imperfect. Besides, during the whole process, there is no credible evaluation for a company's operation efficiency to discover the problems timely not to speak of to solve them, even though the company might have already noticed.

\section{COLlaboRATIVE ANALYSIS OF LOGISTICS AND MANUFACTURE}

\subsection{Connotation of Collaborative Operation}

The concept of collaboration in the supply chain can be described as a sharing process of technology, procedure and

*Address correspondence to this author at the No.1, 2nd Street, Jianggan District, Hangzhou, China, Postcard: 310000; Tel: 13018931723;

E-mail: cychen11@126.com data, cooperated by different economic entities. Through the collaborative operation, it can maximize the service's optimum and the customer satisfactional research. As an efficient cooperation way, collaborative operation is trying to realize all range of information and resource sharing instead of the way of point-to-point. In addition, it links logistics, manufacture and every department in enterprise so that a dynamic logistics alliance and collaboration can be formed to reduce the cost, raise the efficiency and improve the service quality. The essence is the logistics resource optimization of logistics enterprise and manufacturing enterprise. Cohen, Shoshanah [1] divided collaboration into four levels:

Transactional collaboration: The lowest collaboration. It aims at raising the efficiency like formulating a pricing agreement. Ways: manual operations (such as email, phone call and so on).

Cooperative collaboration: It is a one-way collaboration for releasing or visiting like information publishment of the prediction, the inventory or the order. It commits or confirms automatically. Ways: EDI or information portal.

Coordinated collaboration: It is a two-way collaboration for realizing information communication and ability coordination. Ways: VPN, extranet and so on.

Synchronize collaboration: The highest collaboration. It can transfer information synchronously between logistics enterprise and manufacturing enterprise.

\subsection{Principle of Collaborative Operation}

The purpose of collaboration is to realize the system's optimum and efficiency's maximum. By the operation of each subsystem, collaborative system can accomplish a translation from disordered state to ordered state. Meanwhile, it can decline the negative effects in order to make the whole effect maximized. Hence, here some principles that should be followed [2]. 
Fully Satisfy Demand: For adapting the development of manufacturing enterprise, satisfying the logistics meets is the basic function of collaborative operation system. Logistics companies should focus on the convenience, rapidity and safety, taking the advantage of the third-party companies so as to insure the sufficient material and energy supply for the manufacture' developing. On the aspect of quantity, demands include emergency demanding, peak season demanding and so on. On the aspect of quality, demands include multi-level diversity demanding, cargo punctual arrival demanding, and lowest cargo damage demanding and so on.

Overall Profits Optimum: Collaborative system requires utilizing the minimum resource consumption to gain the maximum logistics efficiency and economic profits. For this purpose, to make use of the logistics' superiority, advanced technology and high-efficient organization are demanded. When it comes to transportation program, some physical conditions should be considered like the production scale of the manufacturing company, product features, and geographical location and so on. According to the principle of overall profits optimum, the reasonability of division and collaboration between logistics and manufacture should be increased.

\section{THE PERORMANCE EVALUATION INDEX SYS- TEM OF COLLABORATIVE OPERATION}

\subsection{The Factors of the Performance Evaluation Index}

In this paper, four factors would be argued:

Infrastructure and Staff Quality (ISQ): As the material base and guarantee, it has a direct influence on the collaborative operation and the performance level. According to reference [3], there are four detail indexes: transportation capability(TC), storage capability(SC), handling capability(HC), and practitioner comprehensive quality(PCQ).

Collaboration Management $(\mathrm{CM})$ : it refers to the operator's management capability during the process of operating the collaborative system, which will improve the operating efficiency and reduce the logistics cost. According to reference [4], the following index can reflect this capability: collaboration transportation $\operatorname{cost}(\mathrm{CTC})$, collaboration storage cost (CSC), unit handling cost (UHC) and collaboration degree (CD).

Informationalization Level (IL): In the whole system, information system is the bridge of logistics and manufacture. Without information, collaboration can not carry out. According to reference [5-7], three aspects are included in the informationalization: hardware level (IHL) software linkup level (SLL) and system application degree (SAD).

Consumer Satisfactional Research (CSR): CSR is an important index of performance evaluation. One target of collaboration system is to increase the CSR so that market share and competitiveness would be improved by retaining the regular customers and attracting new customers. CSR is not simply the evaluation to the manufacturing company or logistics company but the entire judgment from ordering, receiving to after service and enterprise service. According to reference [8-10], the followings are included: punctual delivery (PD), delivery accuracy (DA), delivery serviceability (DS) and complaints handling (CH).

\subsection{Questionnaire Survey and Analysis}

In this study, 100 questionnaires were sent and 72 were turned back. The recovery is $72 \%$. According to the rule, both the number and recovery are accepted to reflect the physical situation of collaboration system. Based on the situation, the questionnaire contains two parts. One is mainly for the first level evaluation index and the other is mainly for the second level which is divided from the first. All results release the respondents' general understanding towards the performance level of collaborative operation between relevant logistics enterprise and manufacturing enterprise. Same as the statistics base of fuzzy comprehensive evaluation.

Since the method of marking is different, the way of study is not the same. The questionnaire is designed as four scales. From 1 to 4 , they represent the degree from "very not crucial" to "very crucial". There is detailed explanation in the questionnaire.

Through statistics and analysis, the result of first level can be drawn. As shown in Table $\mathbf{1}$.

Table 1. First level score sheet.

\begin{tabular}{|c|c|c|c|}
\hline Factors & Highest & Lowest & Average \\
\hline \hline $\mathrm{ISQ}{ }^{u_{1}^{(1)}}$ & 4 & 1 & 2.12 \\
\hline $\mathrm{CM}^{u_{2}{ }^{(1)}}$ & 4 & 1 & 3.04 \\
\hline $\mathrm{IL}_{3}{ }^{(1)}$ & 4 & 1 & 2.98 \\
\hline $\mathrm{CSR}^{u_{4}{ }^{(1)}}$ & 4 & 1 & 1.44 \\
\hline
\end{tabular}

Through statistics and analysis, the result of second level evaluation can also be drawn.

The result of second level index of infrastruction and staff quality is shown in Table 2.

Table 2. Evaluation results of infrastructure and staff quality.

\begin{tabular}{|c|c|c|c|}
\hline Factors & Highest & Lowest & Average \\
\hline \hline $\mathrm{TC}_{u_{11}{ }^{(2)}}$ & 4 & 2 & 3.56 \\
\hline $\mathrm{SC}_{u_{12}{ }^{(2)}}$ & 4 & 1 & 2.38 \\
\hline $\mathrm{HC}_{u_{13}{ }^{(2)}}$ & 4 & 1 & 1.44 \\
\hline $\mathrm{PCQ}_{u_{14}{ }^{(2)}}$ & 4 & 1 & 0.93 \\
\hline
\end{tabular}

The result of second level index of collaboration management is shown in Table $\mathbf{3}$.

Table 3. Evaluation results of collaboration management.

\begin{tabular}{|c|c|c|c|}
\hline Factors & Highest & Lowest & Average \\
\hline CTC $u_{21}{ }^{(2)}$ & 4 & 1 & 2.12 \\
\hline $\mathrm{CSC}_{u_{22}{ }^{(2)}}$ & 4 & 1 & 1.47 \\
\hline $\mathrm{UHC}_{u_{23}{ }^{(2)}}$ & 4 & 2 & 1.48 \\
\hline $\mathrm{CD} u_{24}{ }^{(2)}$ & 4 & 2 & 3.56 \\
\hline
\end{tabular}


The result of second level index of informationalization is shown in Table 4.

Table 4. Evaluation results of informationalization.

\begin{tabular}{|c|c|c|c|}
\hline Factors & Highest & Lowest & Average \\
\hline \hline $\mathrm{HL}^{u_{31}{ }^{(2)}}$ & 4 & 1 & 3.02 \\
\hline $\mathrm{SLL}{ }_{32}^{(2)}$ & 4 & 1 & 2.56 \\
\hline $\mathrm{SAD}{ }^{{ }_{33}{ }^{(2)}}$ & 4 & 2 & 2.75 \\
\hline
\end{tabular}

The result of second level index of CSR is shown in Table 5.

Table 5. Evaluation results of CSR.

\begin{tabular}{|c|c|c|c|}
\hline Factors & Highest & Lowest & Average \\
\hline \hline $\mathrm{PD}{u_{41}{ }^{(2)}}^{(2)}$ & 4 & 2 & 3.47 \\
\hline $\mathrm{DA}{u_{42}{ }^{(2)}}_{\mathrm{DS}{u_{43}}^{(2)}}$ & 4 & 2 & 1.94 \\
\hline $\mathrm{CH}{u_{44}{ }^{(2)}}^{(2)}$ & 4 & 2 & 2.81 \\
\hline
\end{tabular}

\subsection{The Performance Evaluation Index System of Col- laboration Operation}

Based on the above studies, followed the established principles, the performance evaluation index system can be constructed. As shown in Table 6.

Table 6. The comprehensive evaluation index system of collaborative operation performance.

\begin{tabular}{|c|c|c|}
\hline Object Layer & $\begin{array}{l}\text { Criterion Layer } \\
\text { (main Factor) }\end{array}$ & Index Layer (Sub Factor) \\
\hline \multirow{15}{*}{$\begin{array}{l}\text { the compre- } \\
\text { hensive } \\
\text { evaluation of } \\
\text { collaborative } \\
\text { operation } \\
\text { performance } \\
\qquad u\end{array}$} & \multirow{4}{*}{$\begin{array}{l}\text { Infrastructure and } \\
\text { Staff Quality } u_{1}^{(1)}\end{array}$} & transportation capability $u_{11}{ }^{(2)}$ \\
\hline & & storage capability $u_{12}{ }^{(2)}$ \\
\hline & & handling capability $u_{13}{ }^{(2)}$ \\
\hline & & $\begin{array}{l}\text { practitioner comprehensive qual- } \\
\text { ity } u_{14}{ }^{(2)}\end{array}$ \\
\hline & \multirow{4}{*}{$\begin{array}{l}\text { Collaboration } \\
\text { Management }_{u_{2}}^{(1)}\end{array}$} & $\begin{array}{l}\text { Collaboration transportation cost } \\
\qquad u_{21}{ }^{(2)}\end{array}$ \\
\hline & & Collaboration storage cost $u_{22}{ }^{(2)}$ \\
\hline & & Handling cost $u_{23}{ }^{(2)}$ \\
\hline & & Collaboration degree $u_{24}{ }^{(2)}$ \\
\hline & \multirow{3}{*}{$\begin{array}{l}\text { Informationaliza- } \\
\text { tion Level } u_{3}^{(1)}\end{array}$} & hardware level $u_{31}{ }^{(2)}$ \\
\hline & & software linkup level $u_{32}{ }^{(2)}$ \\
\hline & & system application degree $u_{33}{ }^{(2)}$ \\
\hline & \multirow{4}{*}{$\mathrm{CSR}_{u_{4}{ }^{(1)}}$} & punctual delivery $u_{41}{ }^{(2)}$ \\
\hline & & delivery accuracy $u_{42}{ }^{(2)}$ \\
\hline & & delivery serviceability $u_{43}{ }^{(2)}$ \\
\hline & & complaints handling $u_{44}{ }^{(2)}$ \\
\hline
\end{tabular}

\section{THE F-AHP BASED EVALUATION MODEL OF COLLABORATION OPERATION}

\subsection{The Weight's Confirmation by AHP}

Talking about index weight, there are statistical analysis method and expert scoring method and so on. In this paper, weight is judged by experts. The experts, specialized in performance evaluation of collaboration operation, scored on the aspects of index layer and criterion layer, and then standardized the marks.

Since every sub-factor's weight $\omega_{\mathrm{ij}}(i=1,2 \ldots, m ; j=$ $1,2, \ldots n)$ is confirmed by the membership of sub-factor $u_{i j}^{(2)}$ to main factor $u_{i}^{(1)}$, weight sets of every sub-factor $u_{i j}^{(2)}$ is $\omega_{i}=\left\{\omega_{i 1}, \omega_{i 2}, \ldots, \omega_{i n}\right\}$, among them, $\sum_{j=1}^{n} \omega_{i j}=1$. Then, according to the influence on the collaboration, every main factor $u_{i}^{(1)}(i=1,2, \ldots, n)$ will be given a relevant weight.

All the remarks, scale scores and level ranking are considered the physical situation, trying to be practical and realistic. There are four levels: $\mathrm{H}=$ \{excellent; good; average; poor $\}$. And the scale score is $\{100 ; 75 ; 50 ; 25\}$.

Based on the former index system, the experts and the professors in the relevant field were invited to score the index system. They are two from Zhejiang Federation of Logistics and Purchasing, three from Taizhou Logistics Federation, three studying high-efficiency of collaboration operation between logistics and manufacture and two leaders from leading logistics enterprise and manufacturing enterprise in Wenling. 10 questionnaires were sent and 10 were received. The recovery is $100 \%$. The final evaluation was figured matrix from the statistics.

1-9 proportion scale is used to evaluate matrix and calculates all the index weight and relevant CR.

By MATLAB program, the judgment matrixes are passed the consistency check. Since the word limits, only the final results are list. (see Tables 1-6).

Through calculation, the first index weight can be seen in Table 7.

$\lambda_{\text {max }}=4.0310, \mathrm{CI}=0.0103, \mathrm{CR}=0.0116$ This judgment matrix is entirely consistent so that the weight is acceptable.

Through calculation, the second index weight under the first index of infrastructure and staff quality can be seen in Table 8.

$\lambda_{\max }=4.0310, \mathrm{CI}=0.0103, \mathrm{CR}=0.0116$ This judgment matrix is entirely consistent so that the weight is acceptable. The consistency of this matrix is acceptable.

Through calculation, the second index weight under the first index of collaboration management can be seen in Table 9. 
Table 7. The first level evaluation index.

\begin{tabular}{|c|c|c|c|c|c|}
\hline & ISQ & CM & IL & CSR & 2 \\
\hline \hline ISQ & 1 & $1 / 3$ & $1 / 2$ & 4 & 0.1601 \\
\hline CM & 3 & 1 & 2 & 3 & 0.4673 \\
\hline IL & 2 & $1 / 2$ & $1 / 3$ & 1 & 0.2772 \\
\hline CSR & $1 / 2$ & $1 / 4$ & $1 / 0954$ \\
\hline
\end{tabular}

Table 8. Factor's score of infrastructure and staff quality.

\begin{tabular}{|c|c|c|c|c|c|}
\hline & TC & SC & HC & PCQ & 4 \\
\hline \hline TC & 1 & 2 & 3 & 3 & 0.4673 \\
\hline SC & $1 / 2$ & 1 & 2 & 2 & 0.2772 \\
\hline HC & $1 / 3$ & $1 / 2$ & $1 / 2$ & 1 & 0.1601 \\
\hline PCQ & $1 / 4$ & $1 / 3$ & 1 & 0.0954 \\
\hline
\end{tabular}

Table 9. Factor's score of collaboration management.

\begin{tabular}{|c|c|c|c|c|c|}
\hline & CTC & CSC & UHC & CD & $1 / 2$ \\
\hline \hline CTC & 1 & 2 & 2 & $1 / 3$ & 0.2628 \\
\hline CSC & $1 / 2$ & 1 & 1 & $1 / 3$ & 0.1409 \\
\hline UHC & $1 / 2$ & 1 & 3 & 1 & 0.1409 \\
\hline CD & 2 & 3 & 1 & 0.4554 \\
\hline
\end{tabular}

Table 10. Factor's score of Informationalization Level.

\begin{tabular}{|c|c|c|c|c|}
\hline & HL & SLL & SAD & W \\
\hline \hline HL & 1 & $1 / 2$ & $1 / 3$ & 0.1634 \\
\hline SLL & 2 & 1 & 1 & 0.2970 \\
\hline SAD & 3 & 2 & 0.5396 \\
\hline
\end{tabular}

Table 11. Factor's score of CSR.

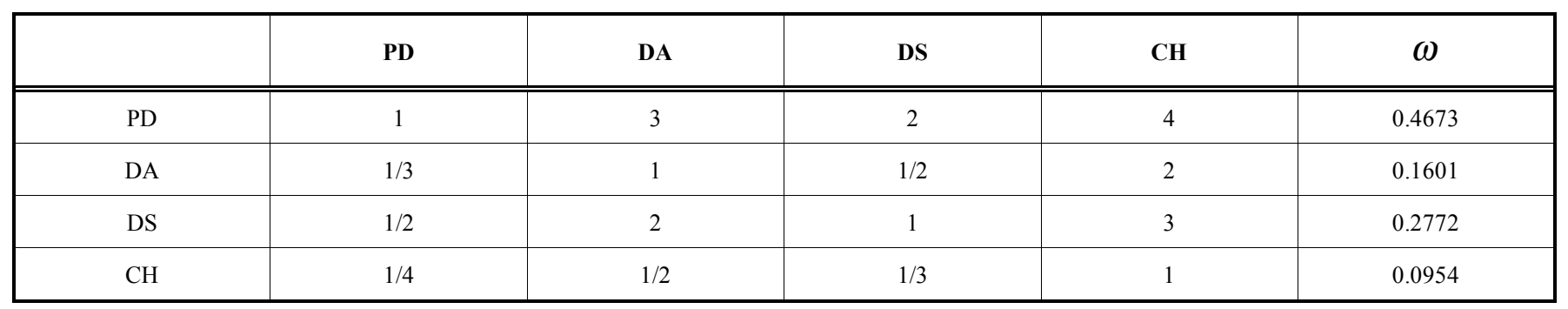

$\lambda_{\max }=4.0104, \mathrm{CI}=0.0035, \mathrm{CR}=0.0039$ This judgment matrix is entirely consistent so that the weight is acceptable.

Through calculation, the second index weight under the first index of informationalization can be seen in Table $\mathbf{1 0}$. $\lambda_{\max }=3.0092, \mathrm{CI}=0.0046, \mathrm{CR}=0.0088$ This judgment matrix is entirely consistent so that the weight is acceptable.

Through calculation, the second index weight under the first index of CSR can be seen in Table 11. 
$\lambda_{\max }=4.0310, \mathrm{CI}=0.0103, \mathrm{CR}=0.0116$ This judgment matrix is entirely consistent so that the weight is acceptable.

In conclusion, the rank of each index can be seen in Table 12 .

Table 12. The rank of each index.

\begin{tabular}{|c|c|c|}
\hline $\begin{array}{c}\text { Criterion Layer } \\
\text { (Main Factor) }\end{array}$ & Index Layer (Sub Factor) & $\omega$ \\
\hline \multirow{4}{*}{$\begin{array}{l}\text { Infrastructure and } \\
\text { Staff Quality } u_{1}^{(1)}\end{array}$} & transportation capability $u_{11}^{(2)}$ & 0.4673 \\
\hline & storage capability $u_{12}{ }^{(2)}$ & 0.2772 \\
\hline & handling capability ${u_{13}{ }^{(2)}}$ & 0.1601 \\
\hline & $\begin{array}{l}\text { practitioner comprehensive qual- } \\
\qquad{\text { ity } u_{14}{ }^{(2)}}^{(2)}\end{array}$ & 0.0954 \\
\hline \multirow{4}{*}{$\begin{array}{l}\text { Collaboration } \\
\text { Management } u_{2}^{(1)}\end{array}$} & $\begin{array}{l}\text { Collaboration transportation } \\
\qquad \operatorname{cost}_{u_{21}{ }^{(2)}}\end{array}$ & 0.2628 \\
\hline & Collaboration storage cost $u_{22}^{(2)}$ & 0.1409 \\
\hline & handling cost $u_{23}{ }^{(2)}$ & 0.1409 \\
\hline & collaboration degree $u_{24}{ }^{(2)}$ & 0.4554 \\
\hline \multirow{3}{*}{$\begin{array}{c}\text { Informationaliza- } \\
\text { tion Level } u_{3}^{(1)} \\
0.2772\end{array}$} & hardware level $u_{31}{ }^{(2)}$ & 0.1634 \\
\hline & software linkup level $_{u_{32}}{ }^{(2)}$ & 0.2970 \\
\hline & System application degree $_{u_{33}{ }^{(2)}}$ & 0.5396 \\
\hline \multirow{4}{*}{$\begin{array}{c}\operatorname{CSR}_{u_{4}}^{(1)} \\
0.0954\end{array}$} & punctual delivery $u_{41}{ }^{(2)}$ & 0.4673 \\
\hline & delivery accuracy $u_{42}{ }^{(2)}$ & 0.1601 \\
\hline & delivery serviceability $u_{43}{ }^{(2)}$ & 0.2772 \\
\hline & complaints handling $u_{44}^{(2)}$ & 0.0954 \\
\hline
\end{tabular}

4.2. The Evaluation System based on Fuzzy Comprehensive Evaluation

Factor sets $U=\left\{U_{1}, U_{2}, U_{3}, U_{4}\right\}=\{$ Infrastructure and Staff Quality,Collaboration Management,Informationalization Level,CSR

$$
\mathrm{U}_{1}=\left\{\mathrm{U}_{11}, \mathrm{U}_{12}, \mathrm{U}_{13}, \mathrm{U}_{14}\right\}=\quad \text { transportation } \quad \text { capability, }
$$
storage capability, handling capability, practitioner comprehensive quality

$\mathrm{U}_{2}=\left\{\mathrm{U}_{21}, \mathrm{U}_{12}, \mathrm{U}_{23}, \mathrm{U}_{24}\right\}=\{$ transportation cost, storage cost, handling cost, collaboration degree $\}$

$\mathrm{U}_{3}=\left\{\mathrm{U}_{31}, \mathrm{U}_{32}, \mathrm{U}_{33}\right\}=\{$ hardware level, software linkup level, system application degree $\}$

$\mathrm{U}_{4}=\left\{\mathrm{U}_{41}, \mathrm{U}_{42}, \mathrm{U}_{43}, \mathrm{U}_{44}\right\}=$ \{punctual delivery, delivery accuracy, delivery serviceability, complaints handling

After the deep investigation and analysis of collaboration operation between logistics and manufacture, the remark sets can be decided as $V=\left(v_{1}, v_{2}, \ldots v_{m}\right)$, among which $v_{t}=(t=1,2, \ldots, m)$ represents different level of remarks from high to low. Four-level scoring is used, which $\mathrm{m}=4$ so that $\mathrm{V}=$ \{excellent; good; average; poor $\}$. Using the equal arithmetic scoring, it can find $v_{i}=(m+1-i) * 100 / m, i=1,2, \ldots, m$. In this example, the full mark is $100, \mathrm{~m}=4$, so the relevant score sets is $V=\{(0,25],(25,50],(50,75],(75,100]$.

During the process, considering the physical situation of collaborative system, varies opinions are accepted from many experts. Besides, some content of the performance evaluation system of the third-party logistics enterprise are also taken into consideration.

\section{CONCLUSION}

How to reduce the logistics cost and promote the enterprise operation efficiency are one of the hot issues in the research field, which means a lot to the logistics and manufacture. Many studies on collaboration system have been done but only few can have a better application effect.

This paper studies the research from the aspect of collaboration operation. With the deep understanding of collaboration system, combining the self-characteristics, it establishes an evaluation system and constructs the evaluation model which is based on AHP and fuzzy comprehensive analysis. It also assesses the whole process.

Although the study makes some achievements in theory and practice, there are still certain shortcomings:

The collaboration system can improve the logistics efficiency and reduce the cost. However, the study on the confirmation of collaboration model and specific mechanism is not very clear.

During the process of founding the model, the method is not very complicated. It can adjust to some simple collaboration system, but, for the complex system, it might be hard to adapt.

\section{CONFLICT OF INTEREST}

The authors confirm that this article content has no conflict of interest.

\section{ACKNOWLEDGEMENTS}

This paper is supported by the Program of the National Natural Science Foundation of China (Grant No. 71171070) and Zhejiang planted talent plan promotion project (Project grant No. 2013R407058).

\section{REFERENCES}

[1] S. Cohen, and J. Roussel, "Strategic Supply Chain Management", New York: McGraw-Hill, 2004.

[2] L. Verdonck, and A. N. Caris, "Collaborative logistics from the perspective of road transportation companies", Transp. Rev., vol. 33, no. 6, pp. 700-719, 2013.

[3] M. D. A. Serna, "Dyna-Colombia", J. Theor. Appl. Inform. Tech., vol. 79, no. 172, pp. 171-179, 2012.

[4] J. Feliu Gonzalez, "Morana for collaborative logistics and freight transport systems", Int. J. Transport. Econ, vol. 40, no. 2, pp. 207$240,2013$.

[5] K. L. Choy, and T. S. Ho, "Computational approaches in enhancing supply chain performance", Int. J. Sys. Sci., vol. 45, no. 6, pp. 1253-1254, 2014.

[6] S. Xian, and D. Qiu, "A fuzzy principal component analysis approach to hierarchical evaluation model for balanced supply chain 
scorecard grading" J. Optim. Theory Appl., vol. 159, no. 2, pp 518535, 2013.

[7] X. Xu, and J. Zhao, "Integrated optimization and deployment mechanism of information resources in complex manufacturing collaborative logistics network", J. Theor. Appl. Inform. Technol., vol. 44, no. 1 pp. 153-160, 2012.

[8] W. T. Yu, and M. A. Jacobs, "The effects of supply chain integration on customer satisfaction and financial performance: An orga- nizational learning perspective", Int. J. Prod. Econ, vol. 146, pp. 346-358, 2013.

[9] L. Li, and J. B. Ford, "Relational benefits and manufacturer satisfaction: an empirical study of logistics service in supply chain", Int. J. Prod. Res., vol. 50, no. 19, pp. 5445-5459, 2012.

[10] J. Wei, and Z. Lu, "Research on multi-agent based collaborative logistics mode", Indust. Eng. Manag., vol. 14, no. 6, pp. 24-27, 2009.

Received: September 22, 2014

Revised: November 30, 2014

Accepted: December 02, 2014

(C) Chen et al.; Licensee Bentham Open.

This is an open access article licensed under the terms of the Creative Commons Attribution Non-Commercial License (http://creativecommons.org/licenses/by-nc/3.0/) which permits unrestricted, non-commercial use, distribution and reproduction in any medium, provided the work is properly cited. 